\title{
BackChat
}

\section{Words not said}

"You'd not swap him for the world", she purred,

Lame, knocked for comfort.

Comfort? My God. Head and limbs cockeyed:

Not swap?

Well then: boys your age don't read Noddy. Don't do cut out dolls

Nor wag a length of string for pleasure.

So what?

Chaps your age think they're great, Somebody;

Cut a dash with the girls,

Shave, talk racy, cockily measure

For size

You struggle for learning, stubborn, yet forgetting diff'rence,

Speak with assurance of fabulous

Promise
Lads in step with manhood Know a Thing,

Sit exams, stand tall,

Loll in seared grasses with Lovely Ones And Kiss

You butt your body's weight, let fly at Sheepish muscles and,

Pond'rous, frail, manhandle feckless legs Like freight ...

... while the go-all blades beef balls about

And shout. They heave their

Shoulders in the scrum, all here-wecome

For fight

Sure, I'd scotch the tumbled chromosomes, Scupper the Bad Guy

Who baulks your days. I'd crank the engine's Turbo.

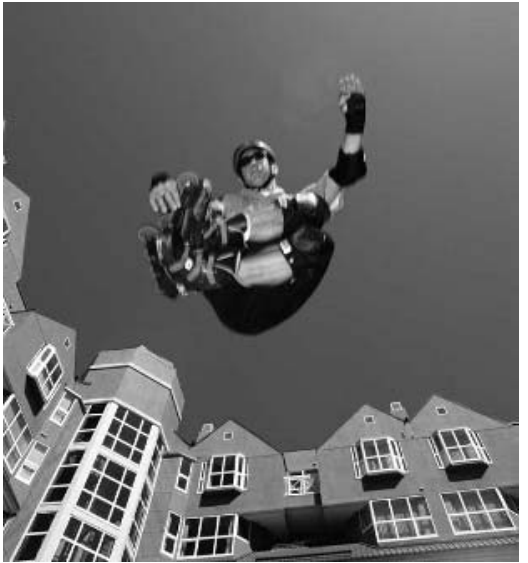

Diana Davenport

Correspondence to: $\mathrm{Dr} \mathrm{H}$ Marcovitch, Syndication Editor, BMJ Publications; h.marcovitch@btinternet.com

\section{Announcement}

Third International Congress on Shwachman-Diamond Syndrome 26-29 June 2005, Robinson College, Cambridge, UK

Papers are invited on the following topics:

Oral and poster presentations, discussion, roundtables

1. What have we learned about SDS? Clinical features; genetic diagnosis

2. Where are we now? Epidemiology; molecular biology; management of clinical problem: gastrointestinal; nutritional; blood \& bone marrow; growth \& skeletal; oral \& dental; developmental \& psychological

3. Where are we going? International collaboration; registries \& databases; prospects for new treatments: genetic; immunogenetic; pharmacological

Further information: Vicky Milner, Procon Conferences Ltd, Tattersall House, East Parade, Harrogate HG1 5LT. Tel: +44 (0)1423 56448; fax: +44 (0)1423 701433; email: vickym@procon-conference.co.uk; www.shwachman-diamondsupport.org 